\title{
Training in psychiatry: making person-centred care a reality
}

\author{
RCPsych Person-Centred Training and Curriculum Scoping Group
}

BJPsych Bulletin (2019) 43, 136-140, doi:10.1192/bjb.2019.13

Correspondence to Jed Boardman (jedboard@atlas.co.uk)

First received 6 Dec 2018, final revision 15 Jan 2019, accepted 12 Feb 2019

(c) The Author 2019. This is an Open Access article, distributed under the terms of the Creative Commons

Attribution-NonCommercial-ShareAlike licence (http://creativecommons.org/ licenses/by-nc-sa/4.0/), which permits non-commercial re-use, distribution, and reproduction in any medium, provided the same Creative Commons licence is included and the original work is properly cited. The written permission of Cambridge University Press must be obtained for commercial re-use.
The RCPsych curriculum for core trainees is currently undergoing review and revision. The Person-Centred Training and Curriculum Scoping Group, which fed into the revision, reported in 2018. This paper shares key findings from the report and offers suggestions on implementing person-centred care in postgraduate psychiatric training and assessment. The scoping group recommended that training and the curriculum should be explicitly person-centred. Among its other recommendations was that skills relating to person-centred practice should be assessed, and the planning, development and delivery of local MRCPsych courses should be coproduced alongside people with lived experience of mental health conditions.

Declaration of interest All authors contributed to the development and writing of College Report CR215.

Keywords Person-centred; recovery; curriculum; core training.

\section{Key learning points. Person-centred care: some training implications}

\section{Curriculum}

- Explicit reference to Person-centred care and RCPsych Values of a Psychiatrist

- Explicit reference to knowledge and skills related to personcentred care, e.g. shared decision-making, therapeutic relationship building, knowledge and application of relevant mental health legislation including human rights law

\section{Training}

- Greater patient involvement in the design and delivery of MRCPsych courses

- Feedback from patients on specific skills, e.g. rapport building, using written communication to establish therapeutic relationship

- Enhanced induction on rotational placements to prepare trainees to practice community engagement and social inclusion

- Embedding formulation skills

\section{Assessment}

- Observed assessment of collaborative care planning (assessment of clinical expertise, mini-assessment of clinical expertise, mini-clinical evaluation exercise)

- Assessment of written communications (e.g. letters addressed to patients)

- Reflections on management of value conflicts
Along with other Royal Colleges, the Royal College of Psychiatrists (RCPsych) presently has the opportunity to review and revise the training curriculum for core trainees. This raises questions about the future challenges for psychiatrists and how training might prepare us for these. ${ }^{1,2}$ One challenge is how to keep the person and citizen at the heart of what we do. This is not confined to the practice of psychiatry. Technical advances are moving modern healthcare towards a more targeted 'precision medicine' approach, but alongside this there is an increasing demand for a more human and personalised approach to care. These developments have been given new urgency by the 2015 UK Supreme Court Montgomery ruling that made shared decision-making based on evidence and values the basis of consent. ${ }^{3}$ Psychiatry's emphasis on aspects of practice such as communication skills, cultural sensitivity and the creation of effective alliances will remain central, but the person should be placed at the heart of our practice.

The RCPsych's Person-Centred Training and Curriculum Scoping Group, which reported in 2018, was set up to examine the implications of a person-centred approach for the curriculum and training for core trainees. ${ }^{4}$ The report emphasises the progressive shift that has taken place in our perspectives of clinical practice: from professional/treatment-centred care to patient-centred care and on to advocacy for person-centred care. Here, we briefly examine the importance of person-centred approaches to practice and their implications for training, the core curriculum and examinations. 


\section{Why emphasise person-centred care?}

There is a considerable international literature on personcentred care. Running through this literature are several consistent themes, including the provision of holistic/biopsychosocial care that is responsive to people's needs and values, treating people with dignity, respect and compassion, empowering them and offering choice, involvement and a partnership approach. ${ }^{5}$ Importantly, the overarching theme is the idea that patients should be 'treated as persons'. ${ }^{6}$ The focus is, first and foremost, on people not patients and embraces the central principle of 'personhood'. This approach is supported internationally by the World Health Organization and the World Psychiatric Association., ${ }^{8,9}$ Importantly, it forms part of both physical and mental health policy in the UK. ${ }^{10,11}$

Person-centredness can be viewed as a dimension of healthcare quality in its own right. ${ }^{12}$ It is outcome focused, as the ingredients of a person-centred approach are key to a professional's role in facilitating personal and social recovery. ${ }^{13}$ At a practice level, General Medical Council (GMC) Fitness to Practice data show that those found unfit for clinical practice are deficient in one or more of the domains of professional practice identified in the Generic Professional Capabilities Framework ${ }^{14}$ (Box 1). This framework will form the basis of all postgraduate curricula, including the core and higher specialist curricula in psychiatry. While all the domains are centred around professional practice influencing patient care, domains 1, 2, 3, 5, 6 and 7 relate more specifically to learning outcomes focused on the quality of the therapeutic relationship between the doctor and patient.

This emphasis on professional values and behaviours may irk some colleagues who question the need to emphasise the person-centred approach because they believe we use this already. In answering this it is important to remember the problems that arise when a compassionate and person-centred focus is missing, as seen a few years ago in Mid Staffordshire. ${ }^{15,16}$ Traditionally, psychiatrists have placed great emphasis on the therapeutic relationship, practitioner/patient interaction, the internal psychodynamics of the person and their broader interpersonal relationships, experiences and abilities. They adopt a biopsychosocial model of health as their core approach to mental health. But in the past 40 years we have seen considerable changes in the way mental healthcare is delivered, alongside dramatic

Box 1. Generic professional capabilities framework domains ${ }^{14}$

1. Professional values and behaviours

2. Professional skills

3. Professional knowledge

4. Capabilities in health promotion and illness prevention

5. Capabilities in leadership and team working

6. Capabilities in patient safety and quality improvement

7. Capabilities in safeguarding vulnerable groups

8. Capabilities in education and training

9. Capabilities in research and scholarship social change, and the future will inevitably bring continuing change. Future generations of psychiatrists will need the skills and capacities that enable us to listen to people who seek our help, to understand and support them in the social context of their lives, and to place an increased emphasis on the active parts they can play as citizens and partners in care processes. Psychiatrists will need knowledge of both biological and social sciences, as well as the ability to adapt to changing social trends and service delivery. ${ }^{2}$

\section{Values-based practice}

There are several lines of argument to support person-centred care, which are outlined in our report. One important line is the ethical case; this values-based argument views personcentred care as respecting autonomy and being a good in its own right. But what are the values that support our clinical practice? The recently published College Report Core Values for Psychiatrists outlines eight core values: communication, dignity, empathy, fairness, honesty, humility, respect and trust. Crucially, these values provide a framework that underpins the delivery of the person-centred care competencies. ${ }^{17}$

We acknowledge that practitioners encounter inevitable tensions in their practice between values and experience, principles and practice, and intention and achievement. Crucially, a person-centred approach can assist here, as it enables psychiatrists to embody and articulate the values of psychiatry in the personal encounter with the person seeking help. Furthermore, to practice in a person-centred way, it is important to inquire about the values of others and to promote partnership in decision-making. This is reflected in the facts of the case that led to the Montgomery judgment, a case in which patient values were not thought to have been given due consideration. This judgment points to the importance of shared decision-making and demonstrates that the acquisition of communications skills for shared decision-making is no longer optional. ${ }^{3}$

Training in values-based practice can be seen as one of the basic building-blocks to provide for future practice and can contribute to the skills needed to deliver person-centred care. This is the case across all psychiatric specialities and is consonant with a recent College report on child and adolescent mental health services. ${ }^{18}$

\section{Person-centred for all?}

The consistent themes set out above ${ }^{5}$ all imply that a person-centred approach can have considerable benefits for people who see professionals and provides an inherent part of positive practice. However, its absence can have negative effects for people and their treatment and wellbeing. We know from people's accounts of using mental health services that they can benefit from a person-centred approach (Box 2). In addition, many studies show beneficial effects of the components of person-centred care on patient outcomes across a range of conditions. ${ }^{5}$ For example, the quality of the relationship between the clinician and a person with a psychosis is associated with better treatment adherence, fewer severe symptoms, better social functioning and fewer hospital admissions. ${ }^{19}$ 
Box 2. Two accounts from people who have used mental health services

This person is a young person with severe obsessive-compulsive disorder who has not yet been able to access qualifications.

'As an inpatient with an anxiety disorder, which causes extreme self-neglect, I felt that I was treated for a long time as if I was just a bad person and I didn't matter. It was like they felt they knew all about me and I knew nothing. At first, I knew when I was being treated wrongly, but eventually I began to doubt myself almost completely. I wasn't aggressive, but they told me I was. I was just angry. I felt I had no power. I tried to turn to my carers, who really tried to help, but I could see that they got bullied too. I could see the staff members who cared, but they seemed eventually to be silent. Things started to change when a clinician joined who started to speak with me in a way that made me feel like they wanted to know about me from me. This clinician helped others to see me differently. It's been really slow, but I am moving on from a very bad experience, with the help of clinicians who include me and respect me'.

This person is a doctor of psychology.

'Early on in my experiences of psychiatric care I did not have any positive interactions or conversations or feel that my psychiatrist understood me. It seemed like the only focus was on what was considered to be wrong with me. It was like everything I had built up in my life before my diagnosis was just wiped away. It was difficult to see myself as anything other than 'a problem'. Then I was fortunate enough to come into contact with a psychiatrist who invited me to join in discussions about my treatment. It was a transformative experience. Others now have radically altered perceptions of me, and my own sense of identity has also changed. I no longer feel as if I am just a patient in someone else's mental health service, because I was treated as a person and that enabled me to start the process of rebuilding my life'.

Person-centred and recovery-oriented practice not only improves the experience of people who use health services, but can also result in greater work satisfaction and reduced stress for professionals delivering healthcare. ${ }^{20-22}$ An important element of person-centred care is the recognition that clinicians are persons/people too, and practitioner well-being is a key determinant of the quality of care provided to patients. Burnt-out and depersonalised practitioners cannot offer person-centred care. ${ }^{23}$ This view emerged strongly in a national survey of trainees that demonstrated the importance placed by trainees on being supported and valued in the workplace. ${ }^{24}$ The health and well-being of professionals provide a key to practising well.

Taking this point a step further, the promotion of an approach that places the person at the heart of what we do provides a strong positive image for psychiatry and can play a part in encouraging recruitment into our specialty. ${ }^{25} \mathrm{~A}$ major recruitment campaign by the RCPsych, \#choosepsychiatry (www.rcpsych.ac.uk/discoverpsychiatry/acareerinpsy chiatry/ choosepsychiatry.aspx) has already highlighted the holistic biopsychosocial, person-focused nature of psychiatry.

We recognise that even when psychiatrists are motivated to practise in a person-centred manner, they may face barriers. For example, conflicting values such as organisational targets or risk management, contradictions related to the compulsory treatment of citizens, and working with offenders who may have antisocial values and beliefs, or with people with reduced decision-making capacity. These circumstances will require adaptations of the person-centred approach to retain its humanistic core.

\section{Modifying the curriculum}

When we examined the present core curriculum, ${ }^{26}$ revised in 2013 and again in 2016, we found that it contained no explicit mention of person-centred care and there was no reference to related concepts such as 'co-production', 'values', 'personalisation', 'personal budgets', 'ethics', 'human rights', 'self-care', 'self-directed care', 'shared decision-making', 'partnership working', 'peer support', the 'value of learning from lived experience'. This list is not exhaustive, but it does reflect the multifaceted nature of a person-centred approach and the need to create a curriculum that is 'person-centred'. Moreover, it points to the need for the language of the curriculum to be updated to reflect a personcentred focus. Consider also that one of the drivers for the current changes in the postgraduate curricula is the recognition that curricula are relevant not only to trainees but also to the public at large, who have an interest in knowing what their doctors are being taught. The new College curricula will need to reflect these changes in both presentation and content.

The content of the curriculum should refer to skills central to a person-centred approach, such as a collaborative or co-productive approach to decision-making; the skills for working with values as well as evidence in shared decisionmaking; coordinated and personalised care, support or treatment; and supporting people to recognise and develop their own strengths and abilities. It should include relational competencies of person-centred care such as shared decisionmaking, self-directed support, co-production, collaborative care and support-planning. Competencies related to broader 
aspects of person-centred care should be included, including personal recovery, values-based practice, human rights, ethics and philosophy, community engagement, spirituality and reflective practice. We should emphasise the value of the study of qualitative methodologies, such as discourse analysis, ${ }^{27}$ in recognition of the role of language in personcentred care. These changes should complement the renewed emphasis in the curriculum on the basic and clinical neurosciences relevant to psychiatric practice.

\section{Postgraduate psychiatric training}

The scoping group's report contained 17 recommendations in five areas. One key area relates to postgraduate psychiatric training, currently largely delivered through MRCPsych courses, which are known to be variable in their content and organisation.

To help understand the current nature of local training courses, the scoping group conducted a survey of MRCPsych courses across the UK, receiving responses from 74 trainees and 15 course organisers. The survey revealed an overwhelming wish for the inclusion of person-centred approaches in psychiatric training by both trainers and trainees. It also found that patients, carers and patient representatives often had peripheral roles in the planning and delivery of MRCPsych courses. Course organisers lacked confidence in knowing how to effectively involve these groups. The implementation of a person-centred curriculum will mean a more central role in training for people who use mental health services, carers and patient representatives. The report recommends the development of guidelines and standards for course organisers to help them embed personcentred care in training placements.

A task and finish group has now been created to ensure patient involvement in the design and delivery of MRCPsych courses. The group will have several examples of good practice to draw upon, including the Expert Patient Programme for undergraduate medical students in Derby, Open Dialogue, and Recovery Colleges. These programmes, based on the principle of collaborative learning, promote person-centred care by helping to reduce the power differential that exists between clinicians and patients. In Derby, undergraduate training is co-delivered by Expert Patients and Psychiatrists, modelling a co-productive and collaborative approach in training that should provide a foundation for shared decision-making and collaborative care planning for future clinical practice.

In the same spirit of partnership and learning from others, the report recommends an increase in opportunities for psychiatric trainees to have joint training sessions with other medical professionals and with other professional groups working in mental health services.

\section{Assessing and examining person-centred care}

An important element in the blueprinting of the curriculum is assessment. Assessment drives learning, and the GMC requires that all essential learning outcomes in the curricula are assessed regularly. Given that person-centred practice is likely to be an essential outcome in postgraduate curricula, trainees can reasonably be expected to be assessed through both formative and summative assessments on their ability to demonstrate a person-centred approach in their clinical practice. Both the Clinical Assessment of Skills and Competencies (CASC) exam, with its multiple simulation stations format, and workplace-based assessments (WPBAs) are well-suited to assess trainees on this domain. However, there are inevitable challenges: person-centred care is not a binary skill and the exam authors will need to display ingenuity in writing stations that can ensure fidelity to real clinical world practice, as well as developing marking schemes that reward person-centred approaches and not merely good 'customer care skills' - a subtle but crucial distinction. Being nice does not equate to being person-centred, and our survey suggests that even trainers/ course organisers may require some training if they are to assess this domain in exams or in the workplace.

\section{The future of training and practice}

On one level, the person-centred report makes the simple, rational, and well-supported assertion that psychiatry should adopt a person-centred orientation for all our work and that the profession should make clear commitments to practice in a values-based fashion to support people in their recovery.

For purposes of training, this implies that the curriculum should be clearly and securely based on a personcentred approach. This approach provides an overarching orientation for psychiatric practice and should be central and explicit throughout the curriculum and the expected values and competencies, not marginal. The approach should focus on the fact that the person is an individual and not solely a patient. A person-focused ethos needs to be at the core of both treatment and engagement, including with respect to healthcare staff and clinicians working with each other. It will require a standard of communication which diminishes stigma and promotes language that is appropriate, respectful and empowering. ${ }^{28}$ The anonymous quotes in Box 2 illustrate the ways that individuals may benefit from person-centred approaches. This reinforces the need to create a curriculum that is values-based, person-centred and recovery focused as a way of connecting with people, establishing partnerships and identifying hoped-for outcomes. In doing so, we would be consolidating many of the past commitments made to practice development by the RCPsych, such as its Joint Position Statement on Recovery ${ }^{29}$ and Fair Deal manifesto. ${ }^{30}$

The growing recognition of the importance of personcentred care in all areas of healthcare has been matched by several positive initiatives aimed at supporting implementation. There have been changes in regulation and medical law, reflecting GMC guidance. The UK Supreme Court's Montgomery ruling has made shared decision-making based on evidence and values the foundation of consent to treatment, ${ }^{3}$ and the National Institute for Health and Care Excellence (NICE) is preparing guidance on shared decisionmaking. ${ }^{31}$ There are also a number of educational initiatives: NICE has set up a joint training programme with the Academy of Medical Royal Colleges and the Collaborating Centre for Values-Based Practice in Oxford on values in shared decision-making, ${ }^{31}$ and the University of West London has established a new Masters programme in 
Person-Centred Care under the joint leadership of Professors Andrew Miles and Michael Loughlin. ${ }^{32}$ It is therefore an opportune time for the College to weave clear links between its person-centred values and the articulation of those values explicitly in the curriculum, their delivery in training through MRCPsych courses and, finally, their assessment through WPBAs and CASC.

Public demand, national policies and legal and regulatory developments in areas such as shared decision-making are driving good medical practice towards more person-centred practice. However, the challenges in implementing training in these areas means that a concerted effort will be needed from trainees, trainers, scheme organisers and indeed the patients and carers we work with. Co-production in training can sow the seeds for collaboration and co-production in clinical practice, and we urge readers to acquaint themselves with the growing body of resources for co-production of training between clinicians and the people who use our services, as signposted in our report.

\section{Acknowledgements}

This report was written by the Person-Centred Training and Curriculum Scoping Group, which consisted of members and non-members of the College, including consultants and trainees. The mixed membership reflected the collaborative and co-productive ethos of both person-centred care and of the RCPsych. Together, the members brought expertise in psychiatric education, clinical psychiatry and lived experience to the scoping group, with many having combined experiences. The members of the group who contributed to this paper were: Jed Boardman, William Burbridge-James, Chris Cook, Subodh Dave, Bill Fulford, Annette Gensale, Rosemary Lethem, Anna Ludvigsen, Veryan Richards, Glenn Roberts, Waldo Roeg, Sue Williams.

\section{References}

1 Fiorillo A, Malik A, Luciano M, Del Vecchio V, Sampogna G, Del Gaudio $\mathrm{R}$, et al. Challenges for trainees in psychiatry and early career psychiatrists. Int Rev Psychiatry 2013; 25(4): 431-7.

2 Lancet Psychiatry Commission. The WPA-lancet psychiatry commission on the future of psychiatry. Lancet Psychiatry 2017; 4: 775-818.

3 Adshead G, Crepaz-Keay D, Deshpande M, Fulford KWMB, Richards V. Montgomery and shared decision making: implications for good psychiatric practice. Br J Psychiatry 2018; 213: 630-32.

4 Royal College of Psychiatrists. RCPsych's Person-Centred Training and Curriculum Scoping Group. Person-Centred Care: Implications for Training in Psychiatry. College Report CR215. RCPsych, 2018 (https://www. rcpsych.ac.uk/improving-care/campaigning-for-better-mental-healthpolicy/college-reports/cr215).

5 Ahmad N, Ellins J, Krelle H, Lawrie M. Person-Centred Care, From Ideas to Action: Bringing Together the Evidence on Shared Decision Making and Self-Management Support. Health Foundation, 2014.

6 Entwistle VA, Watt IS. Treating patients as persons: a capabilities approach to support delivery of person-centered care. Am J Bioethics 2013; 13: 29-39.

7 Anthony WA. The principle of personhood: the field's transcendent principle. Psychiatr Rehab J 2004; 27: 205.

8 World Health Organization. People Centred Healthcare: A Policy Framework. WHO Western Pacific Region, 2007.

9 Mezzich J, Snaedal J, van Weel C, Heath I. The international network for person-centered medicine: background and first steps. World Med J 2009; 55: 104-7.

10 Department of Health. No Health Without Mental Health: A CrossGovernment Mental Health Outcomes Strategy for People of All Ages. Department of Health, 2011.
11 Department of Health. Liberating the NHS: No Decision About Me Without Me. Department of Health, 2012.

12 Berwick D. What 'patient-centered' should mean: confessions of an extremist. Health Aff 2009; 28: w555-65.

13 Shepherd G, Boardman J, Rinaldi M, Roberts G. Supporting Recovery in Mental Health Services: Quality and Outcomes. ImROC Briefing 8. Centre for Mental Health, 2014.

14 General Medical Council. Generic Professional Capabilities Framework. GMC, 2017 (https://www.gmc-uk.org/education/standards-guidanceand-curricula/standards-and-outcomes/generic-professional-capabilitiesframework).

15 Francis R. Report of the Mid Staffordshire NHS Foundation Trust Public Inquiry. TSO (The Stationery Office), 2013.

16 Royal College of Psychiatrists. Driving Quality Implementation in the Context of the Francis Report (Occasional Paper OP92). RCPsych, 2013.

17 Richards V, Lloyd K. Core Values for Psychiatrists (College Report CR204). RCPsych, 2017.

18 Royal College of Psychiatrists. What Really Matters in Children and Young People's Mental Health, Report of the Values-Based Child and Adolescent Mental Health System Commission. RCPsych, 2016.

19 McCabe R, John P, Dooley J, Healey P, Cushing A, Kingdon D, et al. Training to enhance psychiatrist communication with patients with psychosis (TEMPO): cluster randomised controlled trial. $\mathrm{Br} J$ Psychiatry 2016; 209: 517-24.

20 South London and Maudsley NHS Foundation Trust, South West London and St George's Mental Health NHS Trust. Recovery is for All. Hope Agency and Opportunity in Psychiatry (A Position Statement by Consultant Psychiatrists). SLAM/SWLST, 2010.

21 van den Pol-Grevelink A, Jukema JS, Smits $\mathrm{CH}$. Person-centred care and job satisfaction of caregivers in nursing homes: a systematic review of the impact of different forms of person-centred care on various dimensions of job satisfaction. Int J Geriatr Psychiatry 2012; 27: 219-29.

22 Brownie S, Nancarrow S. Effects of person-centered care on residents and staff in aged-care facilities: a systematic review. Clin Interv Ageing 2013; 8: 1-10.

23 Roberts GA. Prevention of burn-out. Adv Psychiatr Treat 1997; 3: 282-9.

24 Royal College of Psychiatrists. Supported and Valued: A Trainee-Led Review into Morale and Training Within Psychiatry. RCPsych, 2017.

25 Choudry A, Faroog S. Systematic review into factors associated with the recruitment crisis in psychiatry in the UK: students' trainees' and consultants' views. BJPsych Bull 2017; 41: 345-52.

26 Royal College of Psychiatrists. Core Curriculum. RCPsych, 2016 (https:// www.rcpsych.ac.uk/docs/default-source/training/curricula-and-guidance/ curricula-core-psychiatry-curriculum-april-2018.pdf?sfvrsn=881b63ca_2).

27 Hamilton B, Manias E. 'She's manipulative and he's right off': a critical analysis of psychiatric nurses' oral and written language in the acute inpatient setting. Int J Ment Health Nurs 2006; 15(2): 84-92.

28 Richards $V$. The importance of language in mental health care. Lancet Psychiatry 2018; 5: 460-1.

29 Care Services Improvement Partnership, Royal College of Psychiatrists, Social Care Institute for Excellence. A Common Purpose: Recovery in Future Mental Health Services. SCIE, 2007.

30 Royal College of Psychiatrists. Fair Deal for Mental Health: Our Manifesto for a 3 Year Campaign Dedicated to Tackling Inequality in Mental Healthcare. Royal College of Psychiatrists, 2008.

31 NICE. Shared Decision Making. NICE, 2018 (https://www.nice.org.uk/ about/what-we-do/our-programmes/nice-guidance/nice-guidelines/ shared-decision-making).

32 University of West London. MSc Person-Centred Health and Social Care. 2019 (https://www.uwl.ac.uk/course/postgraduate/person-centred-healthand-social-care). 